\title{
IS ICE-STREAM EVOLUTION REVEALED BY SATELLITE IMAGERY?
}

\author{
by
}

\author{
S.N. Stephenson
}

(STX, 4400 Forbes Blvd, Lanham, MD 20706, U.S.A.)

and

\author{
R.A. Bindschadler
}

(Code 671, NASA, Goddard Space Flight Center, Greenbelt, MD 20771, U.S.A.)

\section{ABSTRACT}

Ten Landsat Thematic Mapper images together show Ice Streams E, D and most of Ice Stream C on Siple Coast, West Antarctica. The images are interpreted to reveal aspects of both spatial and temporal evolution of the ice streams. Onset of ice-stream flow appears to occur at distributed sites within the ice-stream catchment, and the apparent enhanced flow continues in channels until they join, forming the main ice stream. Most crevassing on these ice streams is associated with features of horizontal dimensions between 5 and $20 \mathrm{~km}$. We suggest these features are caused by bed structures which may be an important source of restraint to ice flow, similar to ice rumples on ice shelves. A pattern of features near the grounding line of the now-stagnant Ice Stream $\mathrm{C}$ are interpreted as having formed because there was a period of reduced flux before the ice stream stopped.

\section{INTRODUCTION}

Weertman (1974) argued that the marine-based West Antarctic ice sheet is potentially unstable. We consider it useful to think of the West Antarctic ice sheet as a system comprised of ice sheet, ice streams and ice shelves. It has been observed that ice streams drain most inland ice (Hughes, 1977) and their velocities fluctuate (Stephenson and Bindschadler, 1988). In an endeavor to increase the physical basis for models that seek to reproduce an ice sheet's response to climatic forcing, we describe features of the ice-sheet system seen in satellite imagery and speculate on the formation of these features. Ice streams are difficult to study on the surface, or even by airborne methods, because of their size and because important features are of ten subtle. Spectrally-enhanced satellite imagery provides the broad spatial coverage to view such large features with enough resolution to see details of motion which are used to infer the nature of ice flow (Lucchitta and Ferguson, 1986). In particular we observe:

(1) that stream-lines develop at distributed points in the ice-stream catchment, often at apparent steps in the bed (McIntyre, 1985) and speculate that the channels of stream-lined flow develop above channeled sub-glacial hydrology that allows fast glacier flow,

(2) that most crevassing in ice streams occurs at surface features which we interpret as reflecting bed structures. We further speculate that these bed structures may significantly resist glacier flow, similar to ice rumples on ice shelves.

(3) that crevasse margins of ice streams can develop along the path of stream-lines and speculate that flow which formed the stream-line caused enough strain-softening to allow the margin to form along that line rather than elsewhere, e.g., directly above a sub-glacial trough edge, (4) linear features which appear to be two divergent northern margins of the now--stagnant Ice Stream C, and we speculate that the pattern of features formed because the ice stream had a reduced flux for an undetermined period before it ceased flowing rapidly.

This study uses ten largely cloud-free TM images acquired of Siple Coast (see Fig. 1) between 1985 and 1987. The images overlap, and cover an area that extends from the catchment of the ice streams to the ice shelf and show Ice Streams $\mathrm{D}$ and $\mathrm{E}$ and most of $\mathrm{C}$, along with the ridges that divide them (see Fig. 1). The main features (described below) were traced from the imagery, and mosaiced together to form Figure 1. Four sub-scenes of these images in Figures 2 to 5 show particular features. In each, TM spectral bands 2,3 and 4 are used because these bands show surface topographic information best (Orheim and Lucchitta, 1988) and features have been enhanced by contrast stretching.

\section{DEFINING PHYSICAL FEATURES}

Ice streams are identified in the imagery by the presence of both undulations and stream-lines and of ten have a distinctive boundary formed by a steeper slope that shows on the imagery as a narrow band (less than $1 \mathrm{~km}$ in width) that is lighter or darker depending on the relative angle of illumination by the sun (Fig. 2). The ice-stream boundaries derived from the imagery and shown in Figure 1 are similar to the mapped boundaries of Rose (1978) Figure 1 also shows internal structure of Ice Streams D and $C$, revealed by stream-lines and identifies channels in the ice-stream catchment that are interpreted as faster flowing because stream-lines occur.

We define "stream-lines" (see Fig. 2) in the same way that MacAyeal and others (1988) define flow-plumes, that is, each stream-line represents the path ice takes after passing over a particular point on the bed of the ice stream. Physically, stream-lines are thin ridges, $1-5 \mathrm{~km}$ in width and a few decimeters (determined from optical levelling on Ice Stream C, Bindschadler and others, 1988) to a few meters in height (Dowdeswell and McIntyre, 1987). In the upper-part of the ice stream and catchment stream-lines tend to be shorter than they are further downstream. Figure 3 shows that stream-line formation appears to be related to ice flow over and around undulations. We speculate they form on the surface when ice flows past a bed undulation which results in lateral redistibution of ice and differential thickening and thinning. In the absence of other severe undulations downstream, surface height variations persist for many kilometers before lateral flow and burial reduce the relief. If steady-state flow exists, an established stream-line would indicate flow direction, but in non-steady-state conditions this connection cannot be assumed (MacAyeal and others, 1988).

In addition to the surface that characterises ice streams the images show two other major patterns of surface relief. Smoother areas (marked $\mathrm{Sm}$ in Fig. 4) typically occur on the ridges between ice streams, and areas that show pronounced undulations (not illustrated) occur in catchment 


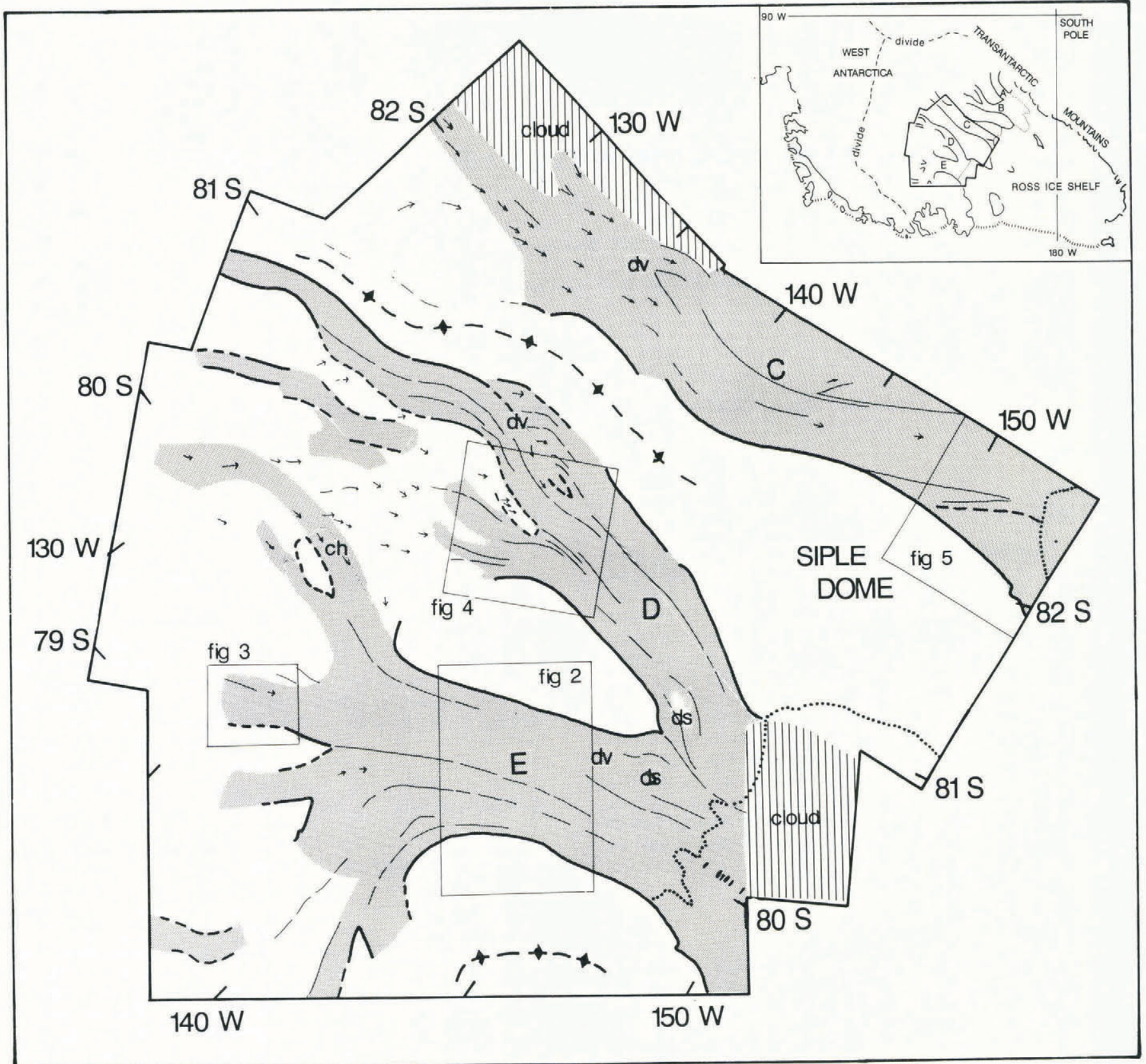

Fig. 1. Outline diagram of main features in the enhanced imagery. Thin lined rectangles are the position of figures 2 to 5 . Thick unbroken lines are ice-stream margins. The line is broken in areas where there appears to be appreciable ice flowing in from the sides. Thick lines with outward pointing arrows are ridge divides. The divide between Ice Stream $\mathrm{D}$ and $\mathrm{C}$ is indistinct. The thick dotted line is the grounding line estimated from the downstream limit of surface undulations. Thin lines deplict selected stream-lines that are continuous or nearly so. The shaded area shows the occurrence of more prominent stream-lines. The boundary between distinct and indistinct stream-lines is, itself, indistinct. Selected short isolated stream-lines are indicated with short thin arrows. "ds" indicates selected areas of disturbed ice, "dv" indicates site of strong divergence.

areas extending at least to the upstream limit of the imagery. There are no measured velocities in the area covered by the imagery except on Ice Stream C where they are of order $10 \mathrm{~m} \mathrm{a}^{-1}$ (Whillans and others, 1987; Thomas and others, 1988), but we interpret areas which have an undulating surface but no stream-lines as having intermediate flow velocities, perhaps tens of meters per year. Also, we guess that the smoothest areas have slower velocities, perhaps only a few meters per year.

\section{INTERPRETATION OF FLOW STRUCTURE}

Stream-lines are the most useful features for inferring the character of ice flow. They occur well into the catchments of Ice Streams D and E, sometimes short and isolated, sometimes clustered in features we term "channels" (shaded grey in Fig. 1). These channels are of ten associated with a reduced number of undulations (for example those marked ch in Fig. 4) and sometimes begin at an apparent step (or series of steps) in the subglacial bed as observed by McIntyre (1985). Most channels continue downstream and join to form the main trunk of the ice stream, but some channels fade out. There are no measured velocities in this area, but we expect the velocity of ice in these channels is higher than for ice outside the channels, and that the velocity decreases in places where the channels become indistinct. In one channel, marked "ch" in Figure 1, there appears to be a small outward flux of ice from the west side. This ice flows into Ice Stream D while most remains in the channel that flows north-west into Ice Stream E. Other examples of similar ice divergence occur elsewhere in the area covered by the imagery, and are labelled " $d v^{n}$ in Figure 1. To summarize, these observations suggest that 


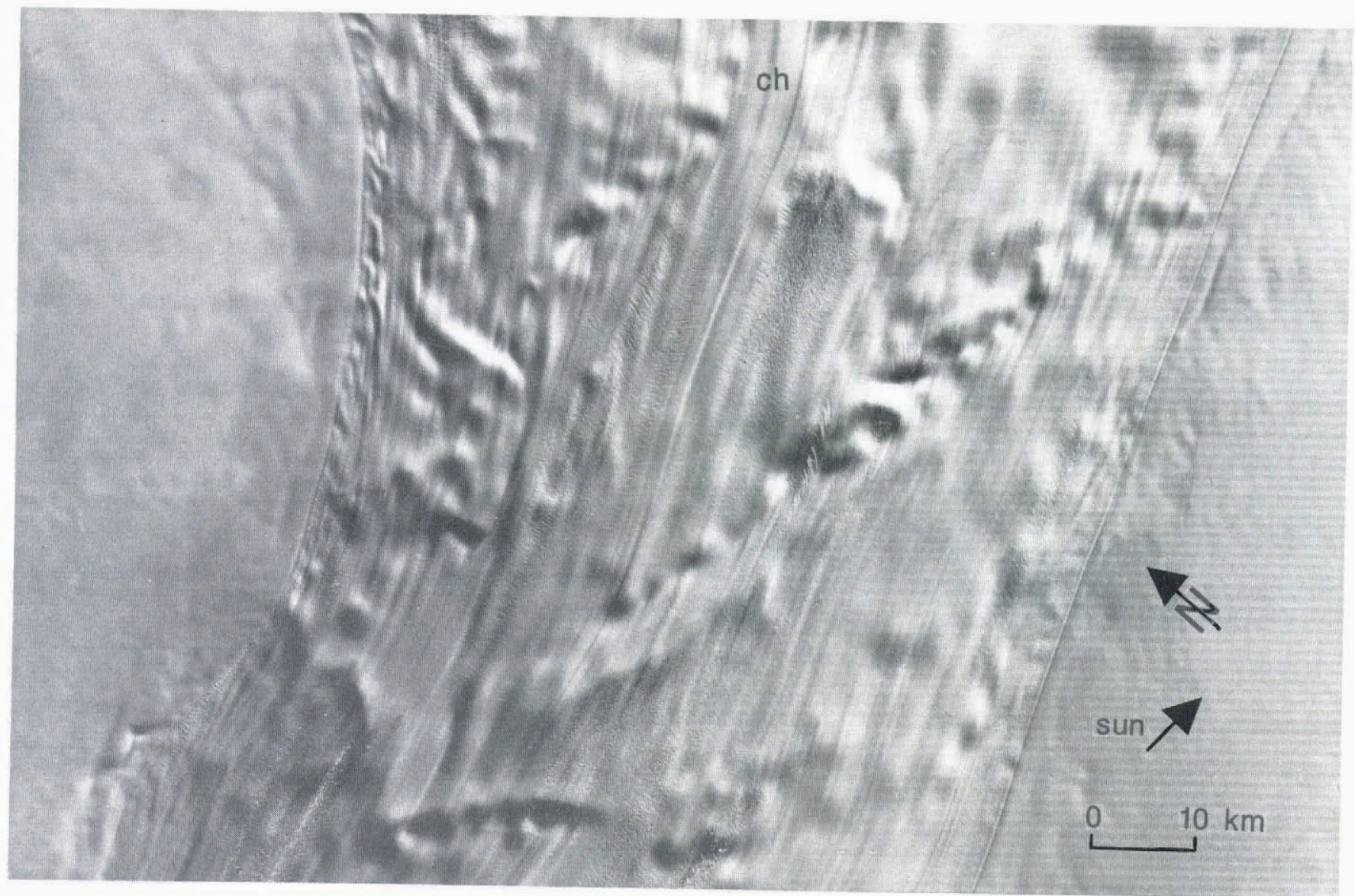

Fig. 2. Enhanced subscene of Thematic Mapper image Y5105215335X0 of the central section of Ice Stream E, showing patterns of undulations and stream-lines and crevasses forming at crest. Flow is from top to bottom.

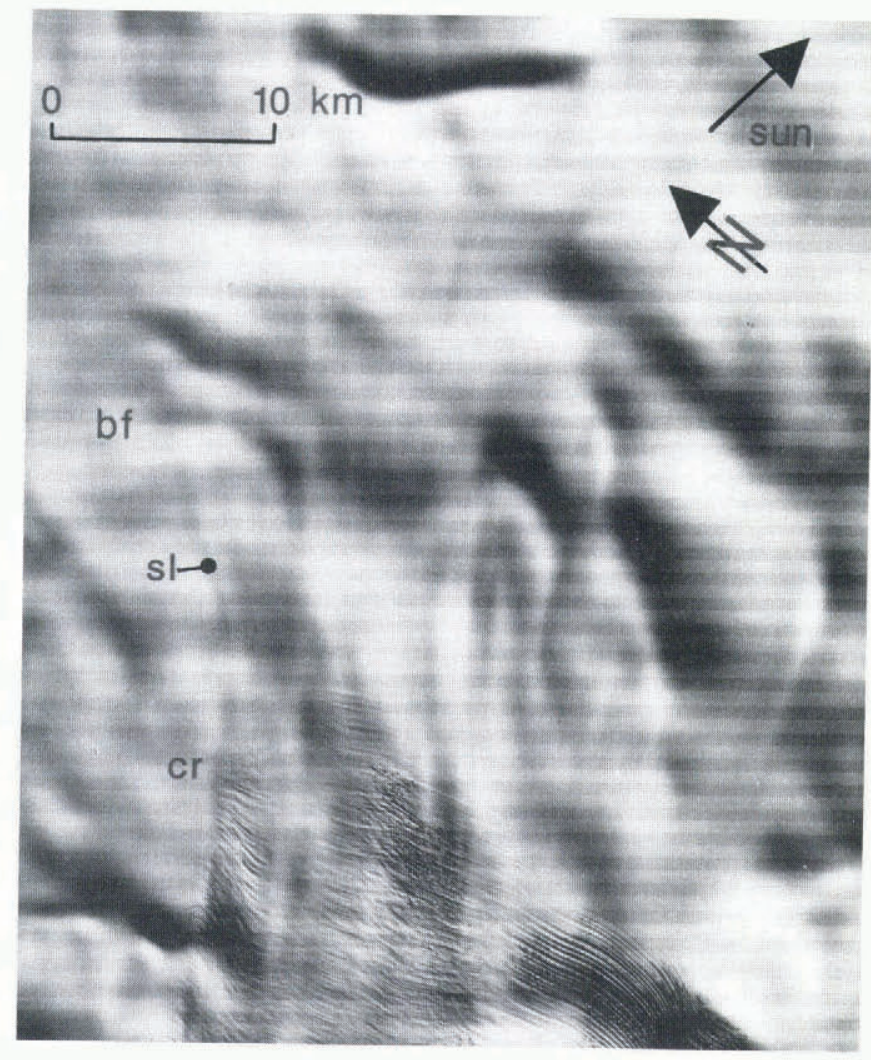

Fig. 3. Enhanced subscene of Thematic Mapper image Y510521533X0 of a small section at the head of Ice Stream E, showing the development of an ice-stream margin. The crevasse onset is labelled cr, and the area of undulations that form the subtle stream-line is labelled bf.

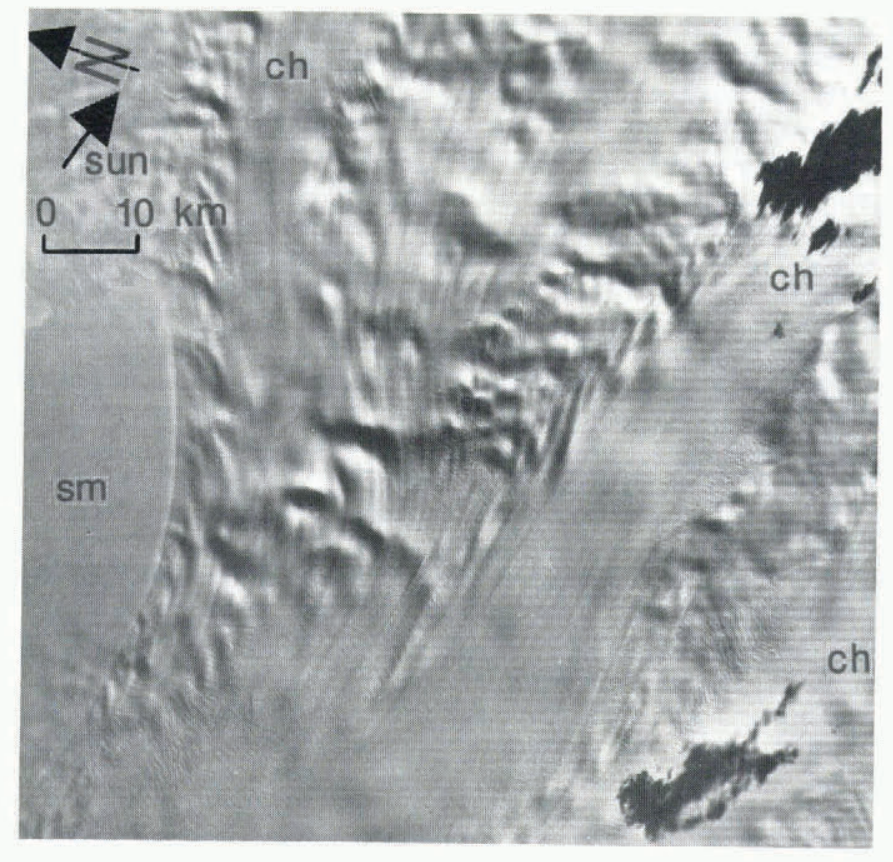

Fig. 4. Enhanced subscene of Thematic Mapper image Y5105114510X0 of the central section of Ice Stream D, showing several channels (labelled $\mathrm{Ch}$ ) within the ice stream. Ice flow is generally from top right to bottom left. The outer boundary of $D$ is seen on the left. Patches of clouds (white) and their shadow (dark) are seen on the right. 


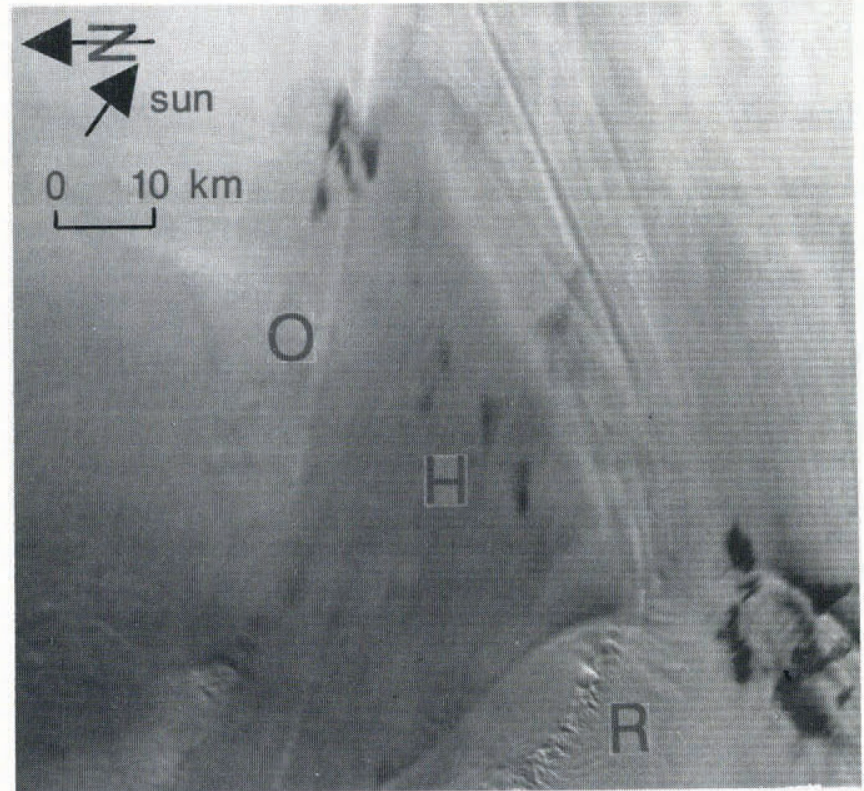

Fig. 5. Enhanced subscene of Thematic Mapper image Y5032913362X0 of the lower section of Ice Stream C The ice stream is on the right of the picture, with the grounding line, a distinct break in slope, in the bottom right of the picture. The outer margin is labelled $\mathrm{O}$, the area of relic rifts is labelled $R$, and the triangular elevated region is labelled $\mathrm{H}$.

ice-stream flow is, in part, initiated in a distributed system of smaller "ice streams" that are embedded in the ice sheet flow regime (catchment area).

On ice streams, the more prominant undulations tend to deflect stream-lines the most. Most creyassing seen on Ice Streams E and D (see Fig. 2) originates at crests of surface undulations and generally the orientations of the crevasses indicate that ice which flows past the undulations has a greater velocity. Blankenship and others (1987) discovered a layer of saturated sediment beneath Ice Stream B which they concluded acts as a lubricant allowing fast glacier flow. Our interpretation of smoother channels within ice streams (marked "ch" in Fig. 2) is that they over-ride thicker layers of saturated sediment, and that the sediment is thin or not present over some of the bumps. We conclude that bed undulations may be a significant source of resistive stress on both Ice Streams E and D, having a similar effect as ice rumples have on ice shelves.

There is less crevassing at the sides of the ice stream than we expected. On Ice Stream B, the northern margin is the most intensely crevassed part of the ice stream, but on both Ice Streams D and E the crevasses at the margin are more laterally concentrated and longitudinally intermittent. Shear along the southern margin of Ice Stream E, (see Fig. 2) may be subdued because further downstream (off the bottom of Fig. 2 but indicted in Fig. 1 by "ds") there is a large disturbed area which probably slows the ice. A similar subdued boundary exists on the north-eastern side of Ice Stream D, and that too may result from a large disturbed area just upstream of the grounding line (also marked ds in Fig. 1). In both cases, these disturbed areas significantly constrict the main channel of flow (Fig. 1) and if they are the cause of a subdued margin, we note that their influence is seen up to $100 \mathrm{~km}$ upstream.

Figure 3 shows the initiation of an ice stream margin in the catchment of Ice Stream E. The margin is defined by a linear band of crevassing and a difference in surface character on each side of the crevasses further downstream. There is no obvious reason either from surface topography or from what we can infer about the bed topography as to why the crevasses occur where they do. Shabtaie and Bentley (1987) showed that ice-stream margins are not usually correlated with boundaries of subglacial troughs. Figure 3 shows that the crevasses (cr) form along the path of a subtle stream-line (sl) which formed at a bedrock feature $15 \mathrm{~km}$ upstream (bf). Hughes (1977) suggested that strain-softening is important for the constitutive properties of the ice margin. We suggest that the pattern of strain causing the stream-line to form also produces a strain-softened fabric which is then carried downstream. We further suggest that margins of ice streams can form at these weak points in the ice sheet rather than form along the edges of subglacial troughs.

\section{EVOLUTION OF ICE STREAMS}

The accepted notion of ice-stream velocity is that it varies little across the stream width except for strong velocity gradients at the sides. This was measured by, for example, Stephenson and Doake (1982) and is termed "plug flow". If our interpretation of the relationship of surface features and ice velocity is correct, then Ice Stream D and $\mathrm{E}$ both experience plug flow without major obstruction for a length of about $160 \mathrm{~km}$ upstream of their grounding lines other than those discussed above and labelled "ds" in Figure 1 . We suggest that these areas develop from the grounding line inwards towards the catchment, and form because the ice stream deposits sub-glacial material, and gradually erodes bedrock highs which exist further upstream and currently cause ice to flow in channels. The head of Ice Stream E forms where channels converge from almost opposite directions. In contrast, the region of channeled flow upstream of Ice Stream D is elongated and constrained between Ice Stream E and the ridge between D and C (see Fig. 1). Although it would appear that Ice Stream D could "capture" ice from Ice Stream E, we conclude (based on our speculation that fast flow is based mainly on basal hydrology) that a significant switch in flux would only follow erosion at the bed allowing water and/or sediment to flow into Ice Stream D.

Recent measurements show that Ice Stream $C$ was active (Rose, 1978) but that it stopped about 200 years B.P. (Shabtaie and Bentley, 1987) while Ice Streams D and E both appear to be in balance within the error of the data (Shabtaie and Bentley, 1987). In general, the surface features of Ice Stream C are similar to Ice Stream D, except that they are more subdued because they are neither being created nor maintained by fast flow and are slowly being buried by snowfall. It is remarkable that if their formation ceased and burial began 200 years ago the snow which has accumulated since (roughly $80 \mathrm{~m}$ ) has not completely obliterated these features which were only a few meters in relief. Upstream of its grounding line, Ice Stream $C$ has two boundaries (Fig. 5). The stream-lines diverge away from the outer boundary of the ice stream around a triangular-shaped area (labelled $\mathrm{H}$ in Fig. 5) that is $30 \mathrm{~m}$ higher in elevation (Bindschadler and others, 1988) and is without stream-lines. Our interpretation is that the high area stagnated first as the ice-stream flux decreased. Because there is little trace of stream-lines or disturbed flow in this area, we deduce that the raised region stopped considerably earlier than 200 years ago. Shabtaie (personal communication) mapped the high area as having the same surface radar signature as the slow moving ice associated with ridges between ice streams. Therefore, the relic linear surface feature indicating the outermost margin of the ice stream has apparently survived considerably longer than 200 years. In addition, we conclude that the band of disturbed ice below the grounding line is a zone of relic rifts (" $R$ " in Fig. 5) that formed during a period when the high area was stagnant and the stream-lined channel was active. If the rifts originally formed at the grounding line, then the distance between the upstream limit of the band and the grounding line (about $2 \mathrm{~km}$ ) divided by the velocity (now about $10 \mathrm{~m} \mathrm{a}^{-1}$ ) would indicate the time the ice stream stopped, about 200 years B.P.. This rough estimate is identical to the estimate of Shabtaie and Bentley (1987). An anonymous reviewer suggested that the separation of rifts from the grounding line may also be explained by grounding line retreat. Thomas and others (1988) measured a $300 \mathrm{~m}$ retreat of the grounding line over a period of 11 years at a site $30 \mathrm{~km}$ away; if this continued at the site of the knolls for about 70 years the $2 \mathrm{~km}$ separation would result. We consider all these estimates very rough, and that the ice stream ceased fast motion within a few hundred years. 


\section{ACKNOWLEDGMENTS}

The imagery was acquired and purchased in collaboration with J. Kelmelis and F. Brownworth of U.S Geological Survey. D. Binnie (U.S. Geological Survey) prepared the initial enhanced imagery, and $M$. Fennel assisted in preparing enhanced images used in the figures. We thank C. Lingle and E. Roberts for useful discussions. Two anonymous reviewers and D. MacAyeal provided thoughtful suggestions. This research was supported by U.S. National Science Foundation grant DPP-8514543.

\section{REFERENCES}

Bindschadler, R.A., S.N. Stephenson, E.P. Roberts, D.R. MacAyeal, and D.R. Lindstrom. 1988. Data report for the Siple Coast Project. NASA Tech. Memo. 100708.

Blankenship, D.D., C.R. Bentley, S.T. Rooney, and R.B. Alley. 1986. Seismic measurements reveal a saturated porous layer beneath an active Antarctic ice stream. Nature, 322(6074), 54-57.

Dowdeswell, J.A. and N.F. McIntyre. 1987. The surface topography of large ice masses from Landsat imagery. $J$. Glaciol., 33(113), 16-23.

Hughes, T.J. 1977. West Antarctic ice streams. Rev. Geophys. Space Phys., 15(1), 1-46.

Lucchitta, B.K. and H.M. Ferguson. 1986. Antarctica: measuring glacier velocity from satellite images. Science, 234(4780), 1105-1108.
MacAyeal, D.R., R.A. Bindschadler, K.C. Jezek, and S. Shabtaie. 1988. Can relict crevasse plumes on Antarctic ice shelves reveal a history of ice-stream fluctuation? Ann. Glaciol., 11, 77-82.

McIntyre, N.F. 1985. The dynamics of ice-sheet outlets. $J$. Glaciol., 31(108), 99-107.

Orheim, O. and B.K. Lucchitta. 1988. Numerical analysis of Landsat thematic mapper images of Antarctica: surface temperatures and physical properties. Ann. Glaciol., 11, 109-120.

Rose, K.E. Unpublished. Radio echo sounding studies of Marie Byrd Land, Antarctica. (Ph.D. thesis, University of Cambridge, 1978.)

Shabtaie, S. and C.R. Bentley. 1987. West Antarctic ice streams draining into the Ross Ice Shelf: configuration and mass balance. J. Geophys. Res., 92(B2), 1311-1336.

Stephenson, S.N. and R.A. Bindschadler. 1988. Observed velocity fluctuations on a major Antarctic ice stream. Nature, 334(6184), 695-697.

Stephenson, S.N. and C.S.M. Doake. 1982. Dynamic behaviour of Rutford Ice Stream. Ann. Glaciol., 3, 295-299.

Thomas, R.H., S.N. Stephenson, R.A. Bindschadler, S. Shabtaie, and C.R. Bentley. 1988. Thinning and grounding-line retreat on Ross Ice Shelf. Ann. Glaciol., $11,165-172$.

Weertman, J. 1974. Stability of the junction of an ice sheet and an ice shelf. J. Glaciol., 13(67), 3-11.

Whillans, I.M., J. Bolzan, and S. Shabtaie. 1987. Velocity of ice streams B and C, Antarctica. J. Geophys. Res., 92(B9), 8895-8902. 